\title{
Research on laser welding of cast Ni-based superalloy K418 turbo disk and alloy steel 42CrMo shaft
}

\author{
Xiu-Bo Liu ${ }^{\mathrm{a}, \mathrm{b}}$, Gang Yu ${ }^{\mathrm{a}, *}$, Jian Guo ${ }^{\mathrm{b}}$, Yi-Jie Gu ${ }^{\mathrm{c}}$, Ming Pang ${ }^{\mathrm{a}}$, \\ Cai-Yun Zheng ${ }^{a}$, Heng-Hai Wang ${ }^{\text {a }}$ \\ ${ }^{a}$ Laboratory for Laser Intelligent Manufacturing, Institute of Mechanics, Chinese Academy of Sciences, \\ 15 Beisihuanxi Road, Beijing 100080, PR China \\ ${ }^{\mathrm{b}}$ School of Materials \& Chemical Engineering, Zhongyuan Institute of Technology, 41 Zhongyuan Western Road, \\ Zhengzhou 450007, Henan Province, P.R. China \\ ${ }^{\mathrm{c}}$ College of Materials Science \& Engineering, Shandong University of Science \& Technology, \\ Qingdao 266510, Shandong Province, P.R. China \\ Received 28 September 2006; accepted 16 November 2006 \\ Available online 22 December 2006
}

\begin{abstract}
Exploratory experiments of laser welding cast Ni-based superalloy K418 turbo disk and alloy steel 42CrMo shaft were conducted. Microstructure of the welded seam was characterized by optical microscopy (OM), scanning electron microscopy (SEM), X-ray diffraction (XRD), energydispersive spectrometer (EDS). Mechanical properties of the welded seam were evaluated by microhardness and tensile strength testing. The corresponding mechanisms were discussed in detail. Results showed that the laser-welded seam had non-equilibrium solidified microstructures consisting of $\mathrm{FeCr}_{0.29} \mathrm{Ni}_{0.16} \mathrm{C}_{0.06}$ austenite solid solution dendrites as the dominant and some fine and dispersed $\mathrm{Ni}_{3} \mathrm{Al} \gamma^{\prime}$ phase and Laves particles as well as little amount of MC short stick or particle-like carbides distributed in the interdendritic regions. The average microhardness of the welded seam was relatively uniform and lower than that of the base metal due to partial dissolution and suppression of the strengthening phase $\gamma^{\prime}$ to some extent. About $88.5 \%$ tensile strength of the base metal was achieved in the welded joint because of a non-full penetration welding and the fracture mechanism was a mixture of ductility and brittleness. The existence of some Laves particles in the welded seam also facilitated the initiation and propagation of the microcracks and microvoids and hence, the detrimental effects of the tensile strength of the welded joint. The present results stimulate further investigation on this field.
\end{abstract}

(C) 2006 Elsevier B.V. All rights reserved.

Keywords: Laser welding; Welded seam; Microstructure; Mechanical properties

\section{Introduction}

Turbocompressor rotor, a core component of turbocompressor, is usually made in China by welding the Chinese cast Ni-based superalloy K418 turbo disk to the quench-tempered Chinese 42CrMo alloy steel shaft. Since the thermal physical and high-temperature mechanical properties of the above two materials are so different (see Tables 1 and 2) and, the Ni-based superalloy possesses great susceptibility to cracking in the heataffected zone (HAZ) during welding. Therefore, their welding process belongs to the typical dissimilar materials welding and

\footnotetext{
* Corresponding author. Tel.: +86 106252 1859; Fax: +86 1062521859.

E-mail address: gyu@imech.ac.cn (G. Yu).
}

usually considered to be a great challenge. At present, the welding methods of these two materials are either electronic-beam welding or friction welding. But the electronic-beam welding process needs vacuum chamber and produces harmful X-rays. On the other hand, the prospect of totally encompassing huge components in a vacuum canopy in order to effect the welding is not practicable. As for the friction welding, low stress destruction are often occurred and welding defects are usually observed near the fusion zone and results in lower production efficiency. For a long time, failures of such joints have plagued Chinese turbocompressor makers [1-3].

Laser welding is a high energy-density, low heat input process with specific advantages over conventional fusion welding processes. These include high welding speed, narrow heat-affected zone, low distortion, ease of automation, single-pass thick 
Table 1

Thermal-physical properties of $42 \mathrm{CrMo}$

\begin{tabular}{rll}
\hline Temperature $\left({ }^{\circ} \mathrm{C}\right)$ & $\begin{array}{l}\text { Specific heat, } \\
C_{\mathrm{p}}\left(\mathrm{J} /\left(\mathrm{kg}^{\circ} \mathrm{C}\right)\right)\end{array}$ & $\begin{array}{l}\text { Coefficient of heat } \\
\text { conductivity, } K \\
\left(\mathrm{~W} /\left(\mathrm{m}^{\circ} \mathrm{C}\right)\right)\end{array}$ \\
\hline 20 & & 39 \\
100 & 470 & 36 \\
200 & 484 & 35 \\
300 & 521 & 34 \\
400 & 560 & 33 \\
500 & 607 & 31 \\
600 & 668 & 29 \\
700 & 745 & 25 \\
762 & 873 & 20 \\
800 & 1075 & 21 \\
900 & 796 & 24 \\
1000 & 684 & 23 \\
\hline
\end{tabular}

section capability and enhanced design flexibility. One of the many features of laser welding is the capability to weld without filler materials (autogenous welding) and it offers distinct advantages [4-8]. Laser welding has recently received growing attention due to its special features and potential. In terms of weldability for metallic materials, Nd:YAG laser has various advantages, such as a high energy absorption rate due to a low reflectivity, a high welding speed, and a low residual stress compared to $\mathrm{CO}_{2}$ laser, so the application of Nd:YAG laser to weld metallic materials is steadily being increased, it has been widely implemented in industrial applications, e.g. in the automotive industry $[9,10]$. But presently, laser power levels are limited for the material thickness involved. However, many more applications could arise following further investigation. In our previous work [11], full penetration butt welding joints between $\mathrm{K} 418$ and $42 \mathrm{CrMo}$ flat plates with $3.5 \mathrm{~mm}$ thickness were successfully made by appropriate selection of processing parameters. In this paper, practical $5.5 \mathrm{~cm}$ thickness $\mathrm{K} 418$ turbo disk and $42 \mathrm{CrMo}$ steel shaft have been tested for butt welding by Nd:YAG laser. The main purpose of this experimental work is to explore the possibility of welding the above turbo disk and shaft in more thickness by laser and enlarge the application scope of laser welding technology, especially in the area of more thickness materials and materials that is difficult to weld by conventional welding methods.

Table 2

Thermal-physical properties of K418

\begin{tabular}{lll}
\hline Temperature $\left({ }^{\circ} \mathrm{C}\right)$ & $\begin{array}{l}\text { Specific heat, } \\
C_{\mathrm{p}}\left(\mathrm{J} /\left(\mathrm{kg}^{\circ} \mathrm{C}\right)\right)\end{array}$ & $\begin{array}{l}\text { Coefficient of heat } \\
\text { conductivity, } K \\
\left(\mathrm{~W} /\left(\mathrm{m}^{\circ} \mathrm{C}\right)\right.\end{array}$ \\
\hline 20 & 529 & 9 \\
100 & 535 & 10 \\
200 & 549 & 12 \\
300 & 573 & 13 \\
400 & 542 & 15 \\
500 & 565 & 16 \\
600 & 602 & 18 \\
700 & 650 & 21 \\
800 & 706 & 23 \\
900 & 763 & 14 \\
\hline
\end{tabular}

Table 3

Chemical composition of K418 (Wt.\%)

\begin{tabular}{ll}
\hline $\mathrm{C}$ & $0.08-0.16$ \\
$\mathrm{Cr}$ & $11.5-13.5$ \\
$\mathrm{Mo}$ & $3.8-4.8$ \\
$\mathrm{Nb}$ & $1.8-2.5$ \\
$\mathrm{Al}$ & $5.5-6.4$ \\
$\mathrm{Ti}$ & $0.5-1.0$ \\
$\mathrm{Zr}$ & $0.06-0.15$ \\
$\mathrm{~B}$ & $0.008-0.020$ \\
$\mathrm{Mn}$ & $\leq 0.50$ \\
$\mathrm{Si}$ & $\leq 0.50$ \\
$\mathrm{P}$ & $\leq 0.015$ \\
$\mathrm{~S}$ & $\leq 0.010$ \\
$\mathrm{Fe}$ & $\leq 1.0$ \\
$\mathrm{~Pb}$ & $\leq 0.001$ \\
$\mathrm{Bi}$ & $\leq 0.0001$ \\
$\mathrm{Ni}$ & $\mathrm{Bal}$ \\
\hline
\end{tabular}

\section{Experimental details}

K418 Ni-based casting superalloy turbo disk and the quench-tempered $42 \mathrm{CrMo}$ steel shaft, with their outer diameter of $38.5 \mathrm{~mm}$ and inner diameter of $27.5 \mathrm{~mm}$, i.e., thickness of $5.5 \mathrm{~mm}$, were selected as the welding components. Tables 3 and 4 showed the detail chemical compositions of these two components. Before welding, any oxide layers and contamination were removed from the surfaces of the components, especially the surfaces needed welding were cleaned with acetone, ethanol and then dried. In order to fasten and collimate these two components, a motor-driven revolving machine platform had been designed and manufactured in our institute, 5 and $15 \mathrm{~L} \mathrm{~min}^{-1}$ flow of high purity argon gas was passed through the molten pool from both top and lateral sides to provide a protective environment for the sake of avoiding the reaction between the molten metals and ambient air.

Experiments of laser welding of the turbo disk and the shaft were conducted on a $3 \mathrm{~kW} \mathrm{Nd:YAG} \mathrm{laser} \mathrm{materials} \mathrm{processing} \mathrm{systems} \mathrm{with} \mathrm{five-axes}$ computer-numerical-controlled (CNC) working station without any filler metal. The employed parameters were based on our previous work, i.e., laser welding of $3.5 \mathrm{~mm}$ thickness flat plates materials. The optimized parameters were: laser output power $3 \mathrm{~kW}$, the shaft revolving speed $8 \mathrm{~mm} / \mathrm{s}$ and the defocus distance $-3 \mathrm{~mm}$. The defocus distance was negative, which was usually employed in order to get more welding seam depth under the condition of welding more thick components [11]. The whole laser welding system was illustrated in Fig. 1. After welding, no post-weld heat treatments were performed.

Metallographic samples and tensile testing specimens were machined by electric discharging cutting, followed by mechanical milling and grinding to acquire the testing surface with roughness of $0.8 \mu \mathrm{m}$ from the slight rough aslaser welding specimens. Metallographic samples of the base metals and the welded seam were prepared using standard mechanical polishing procedures and were etched in $\mathrm{HCl}: \mathrm{HNO}_{3}$ solution in volume ratio of 3:1. Microstructure of the welding seam was characterized by Nephot II optical microscopy (OM), JSM-5800 scanning electron microscopy (SEM) equipped with LinkISIS S-530 energy-dispersive spectrometer (EDS). A D/max-rB high power multi-crystal $\mathrm{X}$-ray diffractometer (XRD) was used for phase identification. The recorded

Table 4

Chemical composition of $42 \mathrm{CrMo}$ (Wt.\%)

\begin{tabular}{ll}
\hline $\mathrm{C}$ & $0.38-0.45$ \\
$\mathrm{Cr}$ & $0.90-1.20$ \\
$\mathrm{Mo}$ & $0.15-0.25$ \\
$\mathrm{Mn}$ & $0.50-0.80$ \\
$\mathrm{Si}$ & $0.20-0.40$ \\
$\mathrm{P}$ & $\leq 0.040$ \\
$\mathrm{~S}$ & $\leq 0.040$ \\
$\mathrm{Fe}$ & Bal. \\
\hline
\end{tabular}




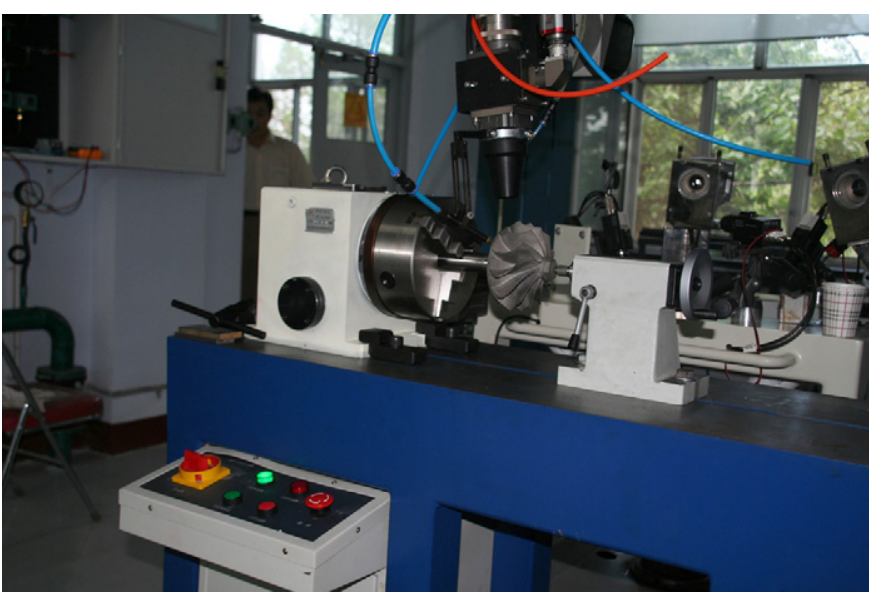

Fig. 1. A picture of the experimental set-up.

intensities and peak positions were compared with Joint Committee on Powder Diffraction Standards (JCPDS) data. The hardness along the transverse and longitudinal direction of the welded seam were measured by an automatic microhardness tester (HXD-1000B, Shanghai Optics Apparatus Ltd., China) with a test load of $1.96 \mathrm{~N}$ and a dwelling time of $15 \mathrm{~s}$. Tensile testing was conducted with a universal testing machine at a crosshead speed of $2 \mathrm{~mm} / \mathrm{min}$ and a gage length of $10 \mathrm{~mm}$. The breaking force $(\mathrm{Bf}: \mathrm{N})$ was recorded when the specimen fractured, after tensile testing, the fracture surface was observed using a scanning electron microscope (SEM) to correlate with the type of fracture.

\section{Results and discussions}

\subsection{Morphology of the welded seam}

The cross-section overview of the laser-welded seam was shown in Fig. 2. It could be seen that no full penetration welded seam had been formed due to the relatively low rated laser output power and the thickness of the components. Shallow concave shape existed in the upper region and remnant metal droplet left at the bottom region and inclined to the K418 alloy side,

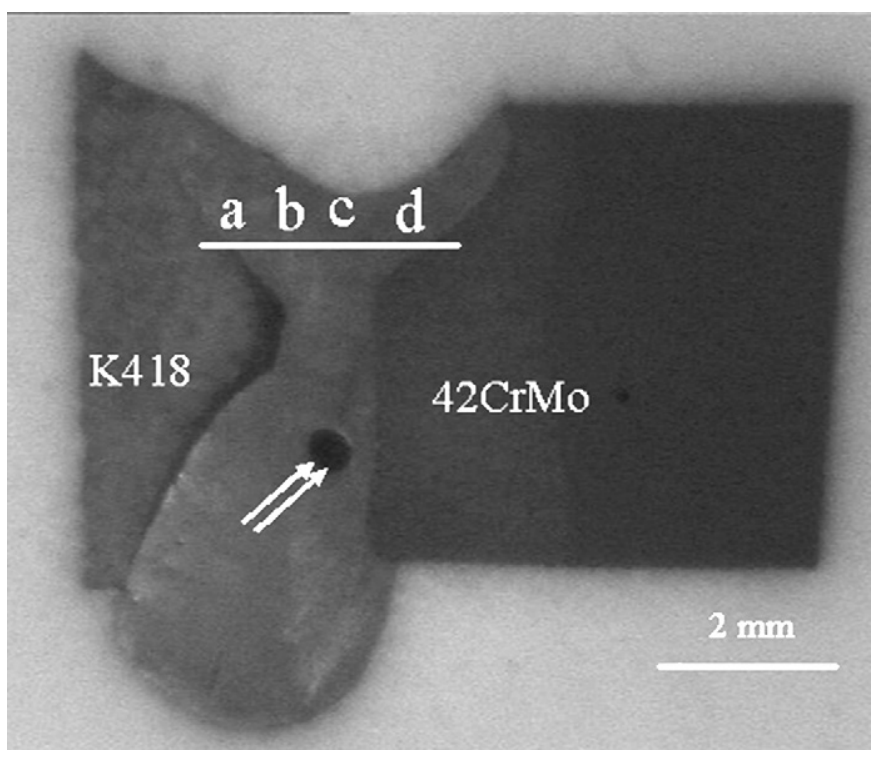

Fig. 2. Morphology of the laser-welded seam between cast Ni-based superalloy K418 turbo disk and alloy steel 42CrMo shaft. which possessed lower thermal conduction coefficient, the detail thermal physical data of these two materials could be seen in Tables 3 and 4. Some large pores, as indicated by the double arrows in Fig. 2, were formed in the central welded seam and inclined to the partially melted zone of $42 \mathrm{CrMo}$, which had the higher melting point and stronger thermal conduction capability. This phenomenon is attributed to the fact that the actual laser scanning speed is relatively slow and much more metals have been melted during the laser direct radiation, thus the shape of the molten pool is dominated by the gravity of the melted liquid metal rather than the molten pool's surface tension. Also, the pores are mainly attributed to the incorporation of shielding gas argon and ambient air surrounding the laser welding system [12]. This result is relatively consistent with other results [13], which showed it was the laser power that had much more influence on penetration depth while welding speed had more influence on weld width.

\subsection{Microstructure examinations}

Laser welding is characterized by extremely high cooling rates (generally of the order of $10^{4} \mathrm{C} / \mathrm{s}$ against $100{ }^{\circ} \mathrm{C} / \mathrm{s}$ in GTA welding), which influences several aspects of weld metal solidification. Our two components, especially K418, being a heavily alloyed material, solidifies in dendritic mode. It is well known that the scale of dendritic structure is inversely proportional to the solidification cooling rates [14]. Thus, the rapid weld metal cooling rates inherent in laser welding are responsible for the formation of relatively fine dendritic structure in the weld fusion zone.

Fig. 3 shows the OM micrographs of the transverse section of the upper part of the welded seam. Fig. 3a-d represents the microstructures of regions a-d in Fig. 2. It could be seen that the solidification microstructure was mainly composed of dendrites whose growing direction was nearly parallel to the negative heattransfer direction, and the dendrites took on the shape of typical directional solidification microstructure. During the process of cooling solidification of the liquid metal, due to the cooling effect caused by the base metals, heat mostly dissipated in the normal direction of the interface, so the temperature gradient in this direction was remarkably dominant, which led to the liquid metal holding the directivity. Under the action of the highest temperature gradient and solidification rate in the normal direction, grains grew with the directional selection, thus forming the dendrites, which were almost parallel to the negative normal direction.

This phenomenon can be explained through the theory of solidification. The mechanical properties of the laser-welded joint are determined by the solidification microstructure, while the solidification microstructure essentially depends on the local solidification conditions (solidification rate $V_{\mathrm{s}}$, temperature gradient at the solid/liquid interface $G$ ), so the ratio of $G$ to $V_{\mathrm{s}}$, namely $G / V_{\mathrm{s}}$, is the critical controlling parameter, which determines the feature of solidification microstructure. When the ratio of $G / V_{\mathrm{S}}$ is rather great, the solidification process prefers forming the dendritic grain structure; while the ratio of $G / V \mathrm{~s}$ is relatively small, the solidification process prefers forming the equiaxed 

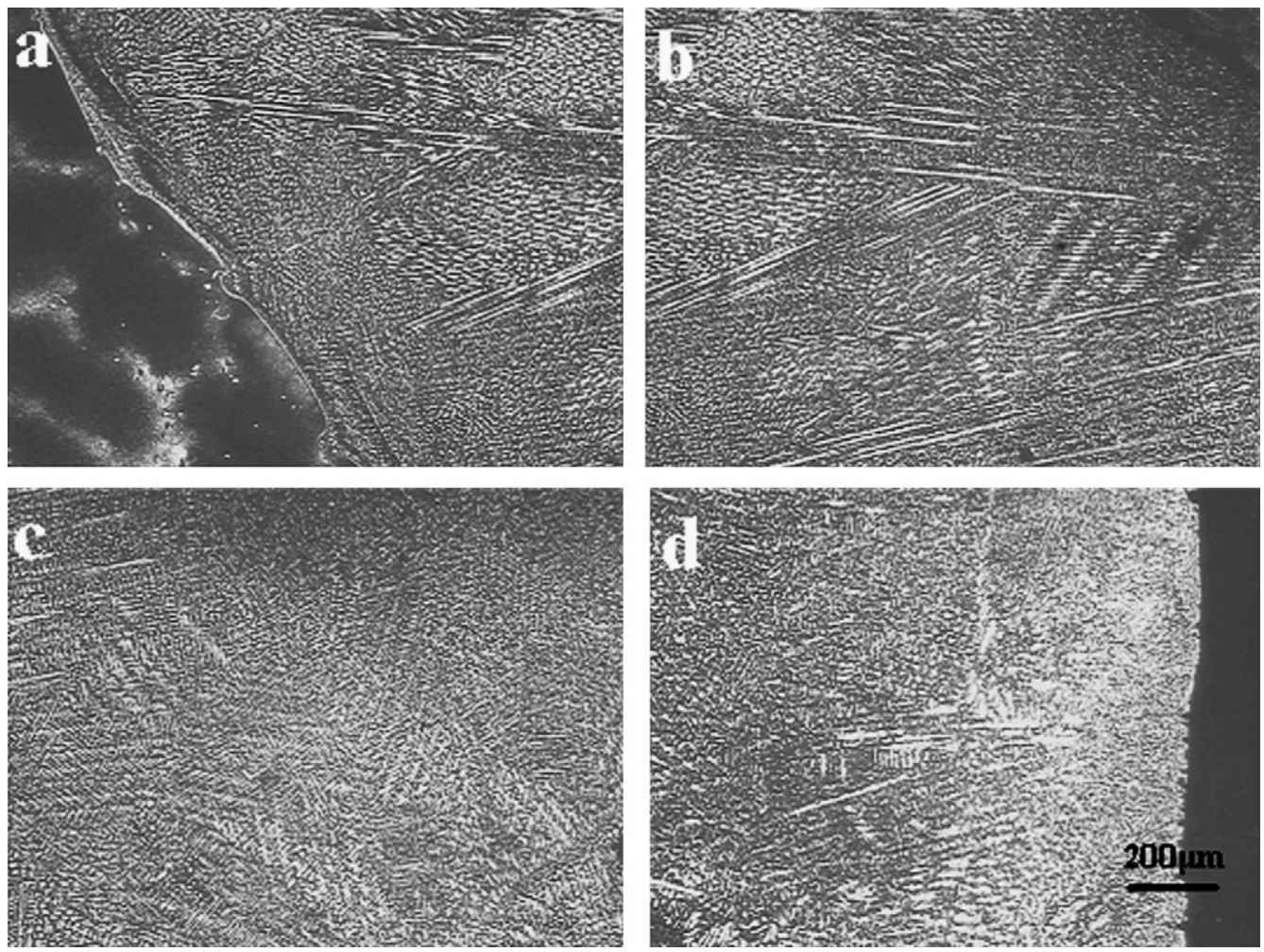

Fig. 3. Typical microstructure of the upper region of the laser-welded seam between cast Ni-based superalloy K418 turbo disk and alloy steel $42 \mathrm{CrMo}$ shaft.

grain structure. During the solidification of the molten pool, as for the region neighboring the interface of the welded seam, the heat dissipation and temperature gradient $G$ are both the greatest in the normal direction. Accordingly, the growing rate of grains in this direction is the fastest than that in any other directions. These growing grains, which possess the directivity obstruct and even merge the grains, which grow in other directions, so the dendrites holding the feature of directional solidification are obtained eventually. However, from interface to the central region of the welded seam, the temperature gradient $G$ in the normal direction gradually decreases. So, in the central region of the welded seam, the temperature gradient $G$ in the normal direction is not dominant any more. Additionally, the process that the heat dissipates from the surface is helpful to the metallic solidification, thus changing the distribution of the temperature gradient $G$ at the central region of the welded seam. As a result, $G / V_{\mathrm{s}}$ in the normal direction in this region decreases substantially, which causes $G / V_{\mathrm{S}}$ in this region does not hold evident directivity any longer, thereby forming the fine-equiaxed grain structure.

Fig. 4 demonstrates the X-ray diffraction result of the welded seam, from which it could be found that in the whole region of the welded seam, the peak of $\left\{\begin{array}{lll}1 & 1 & 1\end{array}\right\},\{200\}$ and $\left\{\begin{array}{lll}3 & 1 & 1\end{array}\right\}$ orientations was quite evident, which manifested that in the central region of the welded seam, the growing directions of grains were rather disorderly, and the solidification microstructure was not the directional solidification dendrite any longer. Other authors [15] found the similar microstructure features in laser metal deposition shaping (LMDS)-fabricated parts, with the decreasing of the $G / V_{\mathrm{s}}$, the microstructures of the laser cladding layer gradually changed from nearly parallel dendrites to the fine-equiaxed grains.

It is interesting to note that a number of regularly spaced bands looping exhibited across the upper region of the welded seam. These bands represented the weld nugget boundaries formed in the laser irradiation. This phenomenon is similar to other authors' results [16], in that case, the spacing between these bands was found to correlate well with welding speed and pulse frequency used for making the weld. In the present case, we proposed that the stirring motion in the melting pool and the Marangoni convection for mixing the alloying elements was effective.

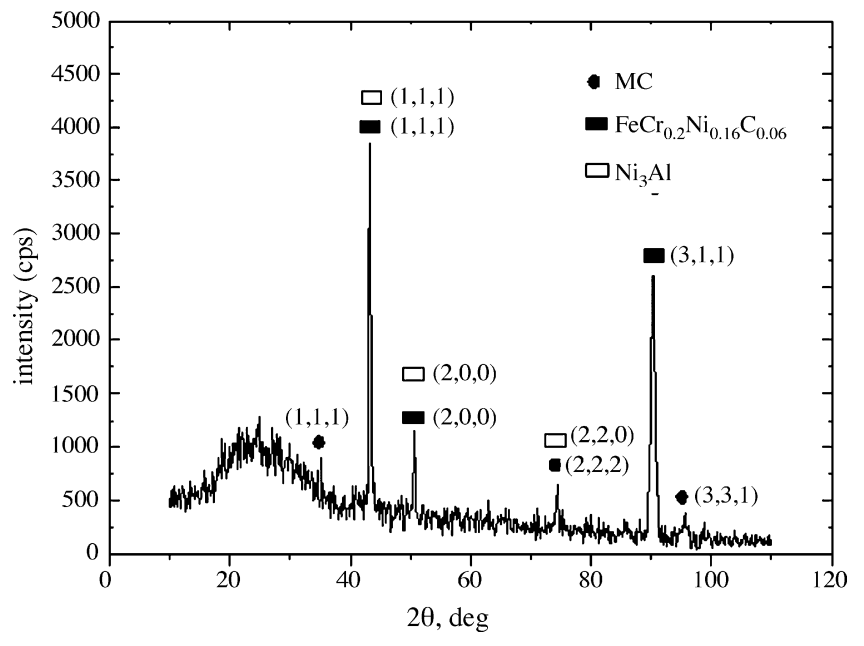

Fig. 4. The X-ray diffraction result of the laser-welded seam. 

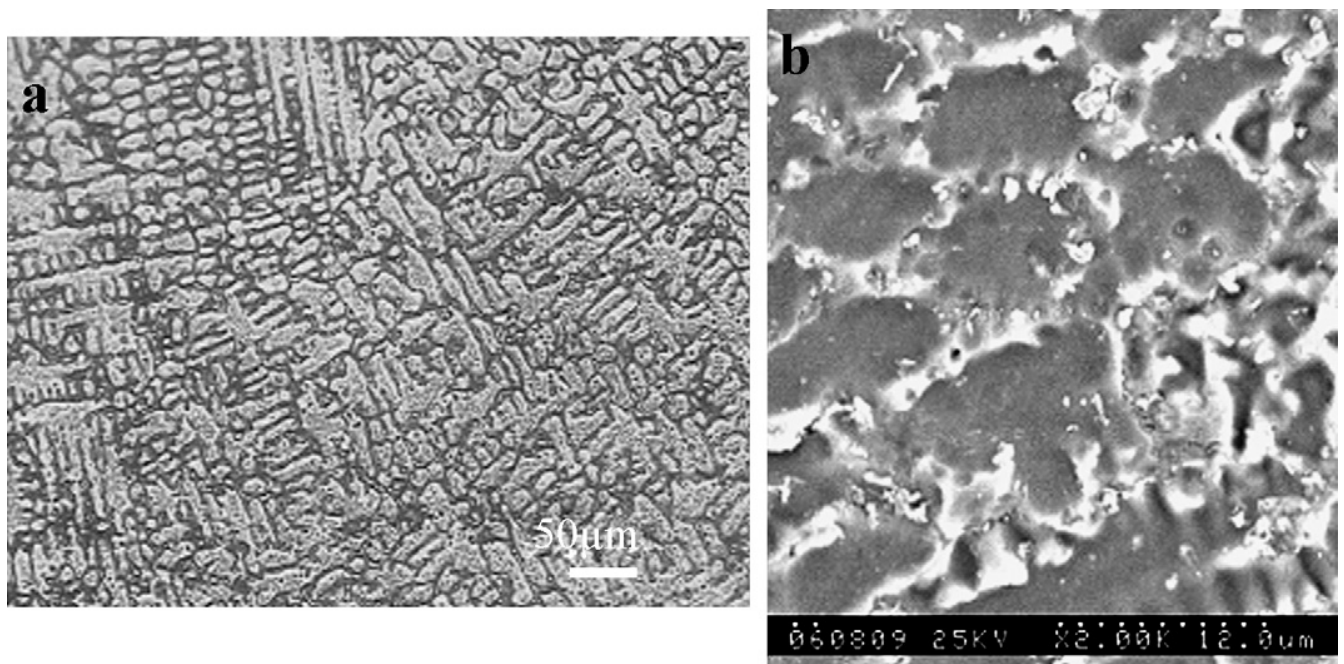

Fig. 5. High magnification of the typical microstructure of the laser-welded seam. (a) OM and (b) SEM photographs showing the non-equilibrium solidified $\mathrm{FeCr}_{0.29} \mathrm{Ni}_{0.16} \mathrm{C}_{0.06}$ solid solution dendrites and dispersed particles as well as small amount of needle-like MC carbides distributed in the interdendritic regions.

At high magnifications, it could be seen from Fig. 5(a) and more clearly in Fig. 5(b) that except the main dendrite structure, which identified by XRD as $\mathrm{FeCr}_{0.29} \mathrm{Ni}_{0.16} \mathrm{C}_{0.06}$ austenite solid solution, and some fine and dispersed particles confirmed by $\mathrm{XRD}$ as $\mathrm{Ni}_{3} \mathrm{Al} \gamma^{\prime}$ phase brought about by the original $\mathrm{K} 418 \mathrm{Ni}-$ based superalloy, some bright etching irregular-shaped particles were found in the interdendritic regions. Image analysis on SEM pictures showed that the amount of the particles were mainly distributed in the interdendrites and minor in the dentritic regions at the weld centre, this phenomenon is similar to the work of Janaki Ram et al. [16], in which case, the similar particles was also mainly segregated in the interdendritic region under the action of relatively low pulsed laser power. The EDS results obtained on these particles was shown Table 5, which indicated that these particles was enriched in $\mathrm{Nb}, \mathrm{Ti}, \mathrm{Mo}$, and lean in $\mathrm{Ni}$, $\mathrm{Cr}$ and $\mathrm{Fe}$ as compared to the $\mathrm{FeCr}_{0.29} \mathrm{Ni}_{0.16} \mathrm{C}_{0.06}$ austenite solid solution dendrites matrix. Chemical composition of the particles enriched in $\mathrm{Nb}$ was identified as $(\mathrm{Fe}+\mathrm{Cr}+\mathrm{Ni}, 73 \mathrm{wt} . \%)$ and $(\mathrm{Ti}+\mathrm{Nb}+\mathrm{Mo}, 27 \mathrm{wt} . \%)$. Considering their small particle size, electron probe microanalysis has a spot size of approximately one micrometer, which is larger than or equal to the particles size, resulting in the incorporation of the matrix material. Synthesizing the above results, it is reasonable to deduce that these particles detected in the interdendrites were the Laves phase, which is a hexagonally close packed (hcp) phase and is generally accepted to be of the form (Ni, Cr, Fe) 2 (Nb, Mo and Ti). The results of Radhakrishna [17] also mentioned that the formation of Laves phase required a niobium concentration ranging from $10-30 \%$. Our quantitative EDS analysis results support that the particles distributed in the interdendritic regions enriched in $\mathrm{Nb}, \mathrm{Mo}$, and $\mathrm{Ti}$, consisted of Laves phase. Incidentally, these regions were depleted in $\mathrm{Ni}, \mathrm{Fe}$ and $\mathrm{Cr}$ contents. It seems that segregation is a prerequisite for the initiation of Laves phase, and segregation is a time-dependent phenomenon and hence, is strongly affected by the welding cooling rate, as influenced by various factors like heat input, welding process, toolings, etc. Slow weld cooling rates result in relatively large dendritic arm spacings compared to rapidly cooled welds, and these coarse dendritic spacings provide congenial/preferential sites for segregation of alloying elements during weld solidification. Even from this point of view, slowly cooled welds employed in this instance are more prone to segregation and hence, the formation of Laves phase. Very recently, reference [18] mentioned the basic similar principle during the preparation of submicron WC$\mathrm{Co}_{\mathrm{p}} / \mathrm{Cu}$ bulk $\mathrm{MMC}_{\mathrm{s}}$ by direct metal laser sintering (DMLS). It had been shown that the micro-distribution of the reinforcing particulates mainly depended on the interaction between the solid particles and the advancing liquid flow. This interaction may lead to trapping or pushing of particulates by solid-liquid interface. At a low WC-Co content, the pushing effect will prevail since the significant Marangoni flows, which were induced by the excessive liquid presented, tend to push the reinforcing particulates towards the center of a laser scan track, thereby resulting in the pile-ups and local segregation of particulates.

As well known, the formation of Laves phase, particularly in solidified structures is detrimental and hence, warrants careful control. Because the formation of Laves phase was found to be mainly due to segregation during weld solidification, any effort

Table 5

EDS analysis results of the laser-welded seam (Wt.\%)

\begin{tabular}{|c|c|c|c|c|c|c|c|c|}
\hline Major elements & $\mathrm{Ni}$ & $\mathrm{Fe}$ & $\mathrm{Cr}$ & Mo & $\mathrm{Al}$ & $\mathrm{Nb}$ & $\mathrm{Ti}$ & $\mathrm{Mn}$ \\
\hline Dendrites & 54.2686 & 32.0260 & 7.6443 & 1.8907 & 0.8260 & 2.3228 & 0.8820 & 0.1397 \\
\hline Particles & 37.9269 & 27.9393 & 8.7532 & 6.0603 & 1.8577 & 12.9591 & 4.5035 & 0 \\
\hline Needles & 45.8429 & 38.2859 & 7.8390 & 3.7596 & 2.0932 & 2.7554 & 1.2801 & 0 \\
\hline
\end{tabular}


to minimize the formation of Laves phase for improved weld properties has to be directed towards minimizing segregation, by control of heat input/cooling rate, using of suitable welding techniques, etc. Unfortunately, since Laves phase is heavily alloyed with multiple elements and its form is very complex as mentioned above, so, no present JCPDS cards could be found to identify the exact existence of it as indicated in Fig. 4. Maybe Transmission Electron Microscope (TEM) is a more powerful tool to analyse the fine structure of the Laves phase. This is currently underway at our laboratory in this respect.

Minor short stick or particle-like phases isolated in the interdendritic regions, as shown in Fig. 5(b), are detected by EDS, the analysis results as shown in Table 5, as enriched in $\mathrm{Ti}$ and $\mathrm{Nb}$ and confirmed as $\mathrm{MC}$ type $(\mathrm{Ti}, \mathrm{Nb}) \mathrm{C}$ carbides on account of the strong affinity of $\mathrm{Ti}$ and $\mathrm{Nb}$ with $\mathrm{C}$ in the molten pool. The incorporation of the matrix material also existed this time due to the small short stick or particles size in EDS analysis. In the first author's previous work [19], in the case of laser surface modification of $\mathrm{TiAl}$ intermetallic alloy by $\mathrm{NiCr}-\mathrm{Cr}_{3} \mathrm{C}_{2}$ precursor mixed powders, large amount of short stick and needle-like TiC carbides were formed near the bonding zone, also support the above analyses to some extent. Because of the small amount, no significant effects about the welded joint's mechanical properties would be expected.

\subsection{The microhardness of the laser-welded seam}

The microhardness is an important index to evaluate the material properties. It depends on both the composition and the microstructure. Fig. 6 exhibits the microhardness distribution plots of the transverse and longitudinal section of the weld seam, respectively. It could be seen that the hardness of the welded seam was the lowest, averaged at about HV220, the microhardness of the HAZ of the K418 was about 400 and then quickly changed to the base metal, i.e., about HV 380. The microhardness of the HAZ of the 42CrMo was the highest, ranged between HV450-HV650 and then gradually transferred to the base metal, about HV250. The longitudinal hardness distribution of the welded seam was nearly fluctuated around HV
240 except for very few higher hardness points, perhaps the very hard MC carbides, which indicating relatively homogeneous microstructure.

This phenomenon can be explained as follows. The hardness of the welded seam is the lowest owing to the partial dissolution of the strengthening phase $\mathrm{Ni}_{3} \mathrm{Al} \gamma^{\prime}$, which was the main strengthening phase and with a large amount in the superalloy K418. The laser induced subsequent non-equilibrium solidification process can suppress the formation of the phase $\mathrm{Ni}_{3} \mathrm{Al} \gamma^{\prime}$ to some extent. Also, the alloy elements coming from the $42 \mathrm{CrMo}$ can result the dilution effects of the molten pool. Therefore, the final amount of the strengthening phase $\mathrm{Ni}_{3} \mathrm{Al} \gamma^{\prime}$ is less than that of the base superalloy K418. Thus, the decreased microhardness of the laser-welded seam. Of course, the reason why the hardness at the HAZ and the base metal of the K418 goes up is due to the relatively more amount of strengthening phase $\gamma^{\prime}$ and the HAZ is very localized because of its lower capability of heat conduction. The reason why the hardness of the HAZ of the $42 \mathrm{CrMo}$ is the highest is due to the self-quenching effects and the formation of a large amount of needle like martensite and the HAZ region is wider than that of $\mathrm{K} 418$ due to its higher coefficient of heat conductivity, especially below $600{ }^{\circ} \mathrm{C}$ (see Tables 1 and 2).

\subsection{The mechanical properties of the laser welding seam}

The normal temperature tensile experiment was performed along the axial direction. As expected, because it was not a full penetration welding, the laser-welded joint fractured within the welded seam, and the ultimate testing tensile strength was $523 \mathrm{MPa}$, which was about $88.5 \%$ of the base metal $42 \mathrm{CrMo}$. By observing the SEM morphologies of fracture appearance of the tensile sample in the upper regions of the welding seam, which was considered to be welded thoroughly, was shown in Fig. 7b, some dimples, with various shape and size were distributed on the fracture surface, some minor spherical particles were detected by EDS as enriched in S and Fe and identified as $\mathrm{FeS}$ or FeS/Fe eutectic welding slags. The dimples indicated that the composition phases possessed certain ductility. In addition,

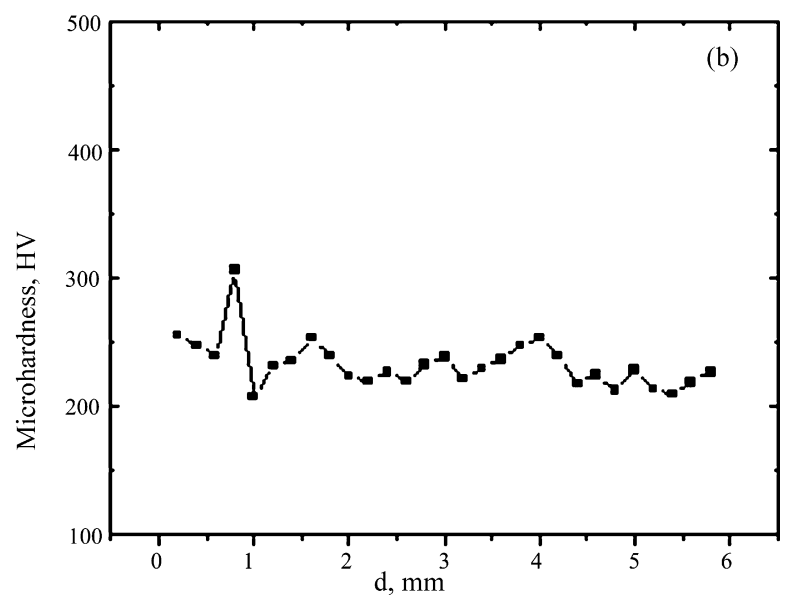

Fig. 6. Microhadrness distribution profiles along the (a) transverse direction and (b) longitudinal direction of the laser-welded seam between cast Ni-based superalloy K418 turbo disk and alloy steel $42 \mathrm{CrMo}$ shaft. 

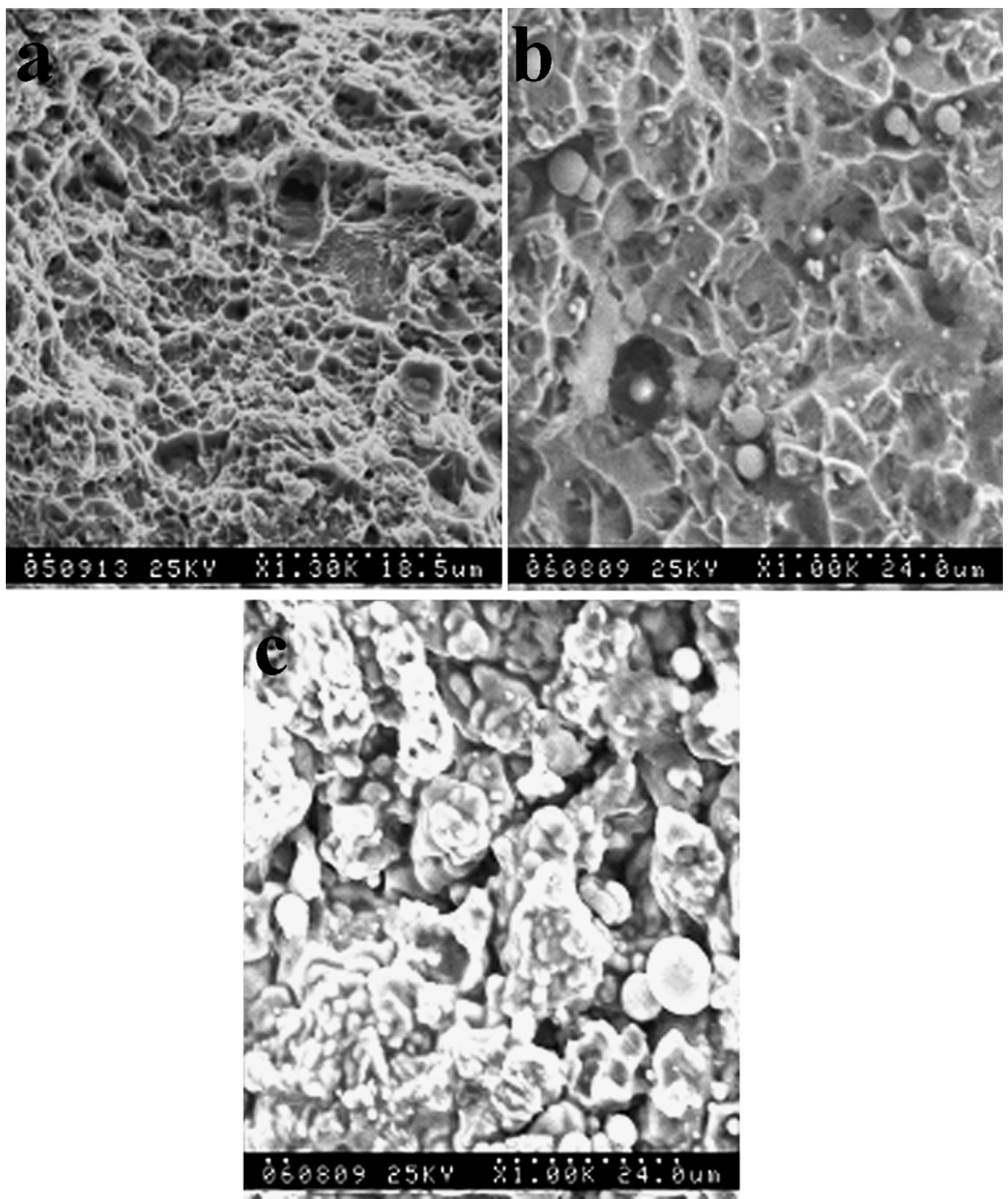

Fig. 7. SEM images showing the tensile fracture surfaces of (a) the base alloy steel $42 \mathrm{CrMo}$ shaft; (b) the welded joint showing the presence of Laves particles inside the dimples and some spherical welding slags; (c) some tearing arris and discontinuous sugar candy shaped fracture features in the partially melted region.

some tearing arris and discontinuous sugar candy shaped fracture could be observed in the partially melted region, as shown in Fig. 7c, which clearly exhibited the debonding along phase (or particle) boundaries, showing a typical intercrystalline fracture. This kind of diverse types of fracture often occurs to the materials with high strength and fine ductility [15]. The appearance of dendritic pattern on the weld fracture surface also indicated that the fracture had taken place preferentially along the interdendritic regions. In contrast, the fracture surface of base material $42 \mathrm{CrMo}$ exhibited predominately dimpled rupture features without any preferentially fracture path (Fig. 7a). The presence of Laves particles inside the dimples on weld fracture surface indicated that microvoids were initiated at the Laves/matrix interfaces (Fig. 7b). It is evident from these observations that Laves parti- cles are another reason responsible for the lower tensile ductility observed in the welded joint compared to base material. Laves particles make the fracture process easier by way of providing favorable sites for excessive microvoids initiation and growth of microscopic cracks along Laves/matrix interfaces resulting in lower tensile strength and elongation.

\section{Conclusions}

The microstructure and mechanical properties of the $\mathrm{CW}$ $\mathrm{Nd}$ :YAG laser-welded joint between cast Ni-based superalloy K418 turbo disk and alloy steel $42 \mathrm{CrMo}$ shaft had been investigated. Microstructure of the laser-welded seam was mainly composed of $\mathrm{FeCr}_{0.29} \mathrm{Ni}_{0.16} \mathrm{C}_{0.06}$ austenite solid solution den- 
drites matrix, some fine and dispersed $\mathrm{Ni}_{3} \mathrm{Al} \gamma^{\prime}$ and Laves particles as well as little amount of short stick or particle-like MC carbides distributed in the interdendritic region. Mechanical tests show that the microhardness of the welded seam decreased compared with the base metal due to the partial dissolution and suppression of the strengthening phase $\gamma^{\prime}$ to some extent. The tensile experiments showed that the welding joint with $88.5 \%$ strength of the base metal was acquired. The fracture mechanism was a mixture of ductility in the fully welded region and brittleness in the partially melted region. Some Laves particles existed in the welded region made the microvoids initiate, microscopic cracks grow and the decreased tensile strength of the welded joint. These results give useful indications for the development of an innovative laser welding technique for the Ni-based cast superalloy K418 turbo disk and alloy steel $42 \mathrm{CrMo}$ shaft. But further work is still needed to make the welded joint with enough tensile strength compared with the base materials and high surface quality and study the corresponding mechanisms thoroughly.

\section{Acknowledgments}

The authors are indebted to Dr. Hong-Wei Song, senior engineer Wei-Jian Ning, engineer Li-Xin Wang of the Laboratory for Laser Intelligent Manufacturing, Institute of Mechanics, Chinese Academy of Sciences, for their invaluable assistance during the laser welding experiments. The work was partially supported by the Qingdao Nature Science Foundation (Grant Number 04-2-JZ-102) and Nature Science Foundation Program of Educational Ministry of Henan Province (Grant Number
2006430017). The authors also wish to thank the reviewers for their constructive suggestions and comments.

\section{References}

[1] D. Sui-Geng, F. Li, W. Jin-Wei, C. Ying, Chinese J. Nonferr. Met. 13 (2) (2003) 323-327 (in Chinese).

[2] D. Suigeng, F. Li, C. Ying, W. Jinwei, J. Northwest. Polytech. Univ. 22 (1) (2004) 112-115 (in Chinese).

[3] G. Yu, H.J. Yu, Integrated Laser Intelligent Manufacturing, Metallurgy Industry Press, Beijing, 2002, pp.68-69.

[4] Z. Sun, J.C. Ion, J. Mater. Sci. 30 (1995) 4205-4214.

[5] Z. Sun, M. Kuo, J. Mater. Process. Technol. 87 (1999) 213-222.

[6] H.M. Wang, Y.L. Chen, L.G. Yu, Mater. Sci. Eng. A 293 (2000) 1-6.

[7] A. Sanderson, C.S. Punshon, J.D. Russell, Fusion Eng. Des. 49-50 (2000) 77-87.

[8] T.A. Mai, A.C. Spowage, Mater. Sci. Eng. A 374 (2004) 224-233.

[9] A. Ribolla, G.L. Damoulis, G.F. Batalha, J. Mater. Process. Technol. 164-165 (2005) 1120-1127.

[10] T.Y. Kuo, H.C. Lin, Mater. Sci. Eng. A 416 (2006) 281-289.

[11] Pang Ming, Yu Gang, Liu Zhao, et al., Chinese J. Lasers 33 (8) (2006) 1122-1126 (in Chinese).

[12] T. Hoon Kim, J. Mater. Sci. Lett. 10 (1997) 400-402.

[13] Y.-T. Yoo, D.-G. Ahn, et al., J. Mater. Sci. 39 (2004) 6117-6119.

[14] S.A. David, J.M. Vitek, in: S.A. David, J.M. Vitek (Eds.), Conference Proceedings on Trends in Welding Research, Gatlinburg, TN, USA, June 1-5, 1992, p. 147.

[15] K. Zhang, W. Liu, X. Shang, Opt. Laser Technol. 39 (3) (2007) 549557.

[16] G.D. Janaki Ram, A. Venugopal Reddy, K. Prasad Rao, G.M. Reddy, J.K. Sarin, Sundar, J. Mater. Process. Technol. 167 (2005) 73-82.

[17] C.H. Radhakrishna, K. Prasad Rao, J. Mater. Sci. 32 (1997) 1977-1984.

[18] Gu Dongdong, Shen Yifu, J. Alloys Compd. 431 (2007) 112-120.

[19] X.-B. Liu, H.-M. Wang, Appl. Surf. Sci. 252 (2006) 5735-5744. 